\title{
Deuterium retention in mixed Be-W-D codeposited layers
}

\author{
M.S. Zibrov ${ }^{1}$, M.J. Baldwin ${ }^{2}$, M. Mayer ${ }^{1}$, H.Q. Nguyen ${ }^{3}$, \\ S. Brezinsek ${ }^{4}$, R.P. Doerner ${ }^{2}$ \\ ${ }^{1}$ Max Planck Institute for Plasma Physics, Boltzmannstrasse 2, 85748 Garching, \\ Germany \\ ${ }^{2}$ Center for Energy Research, University of California San Diego, 9500 Gilman \\ Drive, La Jolla, CA, 92093, United States of America \\ ${ }^{3}$ Department of Chemistry and Biochemistry, University of California San Diego, \\ 9500 Gilman Drive, La Jolla, CA, 92093, United States of America \\ ${ }^{4}$ Institut für Energie- und Klimaforschung, Forschungszentrum Jülich GmbH, 52425 \\ Jülich, Germany \\ E-mail: Mikhail.Zibrov@ipp.mpg.de
}

\begin{abstract}
Mixed beryllium-tungsten-deuterium (Be-W-D) layers (4.4-28.4 at.\% W) were codeposited in a magnetron discharge in $\mathrm{D}_{2}$ - $\mathrm{Ar}$ atmosphere at pressures of $0.8 \mathrm{~Pa}$, $2.7 \mathrm{~Pa}$, and $8 \mathrm{~Pa}$ and a substrate temperature of $373 \pm 15 \mathrm{~K}$. The composition of the layers was determined using nuclear reaction analysis and Rutherford backscattering spectrometry. D trapping states in the layers were examined using thermal desorption spectroscopy. At all pressures used, the D concentration in the layers has a nonmonotonic dependence on the $\mathrm{W}$ concentration, with the maximum occurring at 4.4$7.3 \% \mathrm{~W}$. In this case, the $\mathrm{D}$ concentration is about two times greater than that in a Be-D layer; in W-D layers the D concentration is more than one order of magnitude smaller. Increase of pressure during deposition results in an increase of the $\mathrm{D}$ concentration in Be-D and Be-W-D $(4.4-7.3 \% \mathrm{~W})$ layers and is linked with the appearance of sharp low-temperature D release peaks near $450 \mathrm{~K}$ and $500 \mathrm{~K}$. Increase of pressure also results in steeper decrease of the $\mathrm{D}$ concentration with increasing $\mathrm{W}$ concentration beyond 7.3\%. It is concluded that for the layers deposited at $450 \mathrm{~K}$ and above, the effect of the presence of $\mathrm{W}(4.4-28.4 \%)$ on the D retention becomes small.
\end{abstract}

Keywords: Deuterium retention, Thermal release, Beryllium, Tungsten, Mixed materials, Codeposition

Published in: Nuclear Fusion 60 (2020) 126005 


\section{Introduction}

Erosion of the beryllium (Be) first wall and the tungsten (W) divertor in ITER followed by transport of eroded species and their redeposition can result in formation of mixed material layers in some areas. Such layers have been found in JET operating with the ITER-like wall [1, 2, 3, 4]. Fuel species (deuterium (D) and tritium (T)) impinging onto growing layers can get implanted and trapped in them [5, 6, 7]. This process is called codeposition (or co-implantation). It was found to be the dominant mechanism of fuel retention in JET [8] and is anticipated to play a similar role in ITER [6, 9]. $\mathrm{D}$ codeposition with Be [10, 11, 12, 13, 14] and $\mathrm{W}$ [10, 15, 16, 17] has been previously studied in detail. Considering the low erosion yield of $\mathrm{W}$ and much lower $\mathrm{D}$ concentration in W codeposited layers as compared with Be layers, it is expected that codeposition with Be will dominate the $\mathrm{T}$ inventory in ITER [6]. Therefore, the current projections of $\mathrm{T}$ accumulation in ITER are made assuming only pure Be codeposited layers [6, 9]. However, mixed material layers can exhibit different $\mathrm{D}$ and $\mathrm{T}$ trapping and thermal release characteristics than pure Be layers. It was observed that the presence of carbon (C) in Be layers considerably increases the D retention [14]. On the other hand, the presence of oxygen $(\mathrm{O})$ [7, 14, helium $(\mathrm{He})$ [18], and nitrogen $(\mathrm{N})$ [14, 19] in Be layers has only a small effect on D retention. Currently, very little is known about the effect of $\mathrm{W}$ presence in Be layers. Dinca et al. [20], Jepu et al. 21], Mateus et al. [22], and Sugiyama et al. 23] studied D implantation into deposited Be-W layers. However, D incorporation in a layer during its growth (codeposition) can differ considerably from D implantation into a deposited layer. Very limited studies of Be-W-D codeposition were made only by Dinca et al. [24]. Therefore, there is a need to understand D codeposition mechanisms with mixed Be-W materials in order to make more reliable predictions of the $\mathrm{T}$ inventory and the efficiency of $\mathrm{T}$ removal by baking [25].

This contribution is devoted to the investigation of $\mathrm{D}$ retention in Be-W-D codeposited layers of various composition. The emphasis is put on studying layers with low W content $(<30 \%)$, similarly to the layers found in JET $(\leq 10 \%)[3]$ and to layers that can be expected in ITER. The effect of gas pressure during deposition is also investigated with the effort in obtaining data at high pressures, which will be preferred in the ITER divertor for power handling reasons [26].

\section{Experimental details}

\subsection{Layer deposition}

Layers were deposited onto $10 \times 10 \mathrm{~mm}^{2}$ molybdenum (Mo) plates and (100) silicon (Si) wafer pieces. Mo samples were ground with $\mathrm{SiC}$ sandpaper, ultrasonically cleaned in ethanol and acetone, and then degassed in vacuum $\left(\sim 10^{-5} \mathrm{~Pa}\right)$ at $1250-1300 \mathrm{~K}$ for $1 \mathrm{~h}$. Although Be-containing layers in ITER will be deposited predominantly on W tiles, Mo substrates were used in the present study to be able to quantify the $\mathrm{W}$ content in the layers by ion beam analysis (IBA) methods. Since Mo and W both have a body 
centered cubic crystal structure and very close lattice parameters, layers deposited on Mo and $\mathrm{W}$ are expected to have similar microstructures.

Depositions were carried out in a DC magnetron sputtering device equipped with four independent sources in a confocal arrangement at the PISCES laboratory [11, 13]. The base pressure in the deposition chamber below $2 \times 10^{-4} \mathrm{~Pa}$ is obtained using a cryogenic pump. Mixed layers were deposited using three Be and one W sputtering targets. To obtain layers with different $\mathrm{W}$ concentrations, Be sources were operated at $100 \mathrm{~W}$ while the power on the $\mathrm{W}$ source was varied in the range of $1-100 \mathrm{~W}$. A mixture of $\operatorname{Ar}(40 \mathrm{sccm})$ and $\mathrm{D}_{2}(50 \mathrm{sccm})$ was used as working gas. The $\mathrm{D}_{2}$ fraction in the mixture, determined by a capacitance gauge, was $p_{\mathrm{D}_{2}} / p_{\text {total }}=14-16 \%$. The working pressure during a deposition $p_{\text {total }}$ was feedback-controlled by a throttle valve between the deposition chamber and the cryogenic pump. Depositions were performed at pressures of $0.8 \mathrm{~Pa}, 2.7 \mathrm{~Pa}$, and $8 \mathrm{~Pa}$, covering the expected divertor neutral pressure range in ITER [26]. Four substrates (three Mo and one $\mathrm{Si}$ ) are placed in circular depressions in a rotating $(0.3 \mathrm{~Hz})$ holder at the same radial distance from its center. The holder is biased to $-80 \mathrm{~V}$. An additional ring electrode located a few $\mathrm{mm}$ above the holder is biased to $+44 \mathrm{~V}$. The current density on the holder during depositions was in the range of $0.2-0.4 \mathrm{mAcm}^{-2}$.

The holder temperature is monitored during the deposition by a K-type thermocouple pressed against a circular trench on the front side of the holder. It is assumed that the samples and the holder have close temperatures. The heat flux from the sputter sources warms the samples and the holder during layer deposition. No external heating/cooling of the holder is applied. The sources were operated when the holder temperature was within $\pm 15 \mathrm{~K}$ of the desired temperature. That is, the temporal evolution of the holder temperature is sawtooth-like: heating when the sputter sources are on and cooling when they are off [11]. Most of the depositions were carried out at the sample holder temperature of $373 \pm 15 \mathrm{~K}$. In this case, the initial heating of the holder from room temperature to the lower boundary of the temperature window $(358 \mathrm{~K})$ was small (up to $300 \mathrm{~s}$ ) compared with the total deposition time (at least $1800 \mathrm{~s}$ ). Codeposits in ITER are expected to form on components with a surface temperature of $373 \mathrm{~K}$ and higher [9, 25]. The maximum deposition temperature in the present study was limited to $523 \pm 15 \mathrm{~K}$.

Due to the technical limitations of the setup, it was not possible to perform plasma characterization. As in typical DC magnetron plasmas, the electron temperature is expected to be in the range of $1-10 \mathrm{eV}$ and should mainly depend on the gas pressure [27. The plasma density near the sample holder estimated from the ion current density using the Bohm criterion is in the range of $10^{15}-10^{16} \mathrm{~m}^{-3}$. It depends mainly on the gun power and to a lesser extent on the gas pressure. The incident ion energy is defined by the applied bias voltage of $-80 \mathrm{~V}$. The contribution of the plasma potential is expected to be small. Based on the previous studies of mixed Ar- $\mathrm{D}_{2}$ plasmas [28, 29, 30], it can be expected that the dominant ion species are: $\mathrm{Ar}^{+}, \mathrm{ArD}^{+}, \mathrm{D}_{3}^{+}$, and $\mathrm{D}_{2}^{+}$. Their abundance can depend on the gas pressure [30]. In addition, the gas pressure affects the neutral- 
ion collisionality in the sheath. Although we are not able to assess the contributions of these effects, we expect that in all experiments the incident ion energy does not exceed $40 \mathrm{eV} / \mathrm{D}$. Due to the relatively low plasma density, the sputtered Be and W atoms will arrive at the substrate mostly as neutral atoms [31].

All used deposition conditions and the main characteristics of the deposited layers are summarized in Table 1 . 
Deuterium retention in mixed Be-W-D codeposited layers

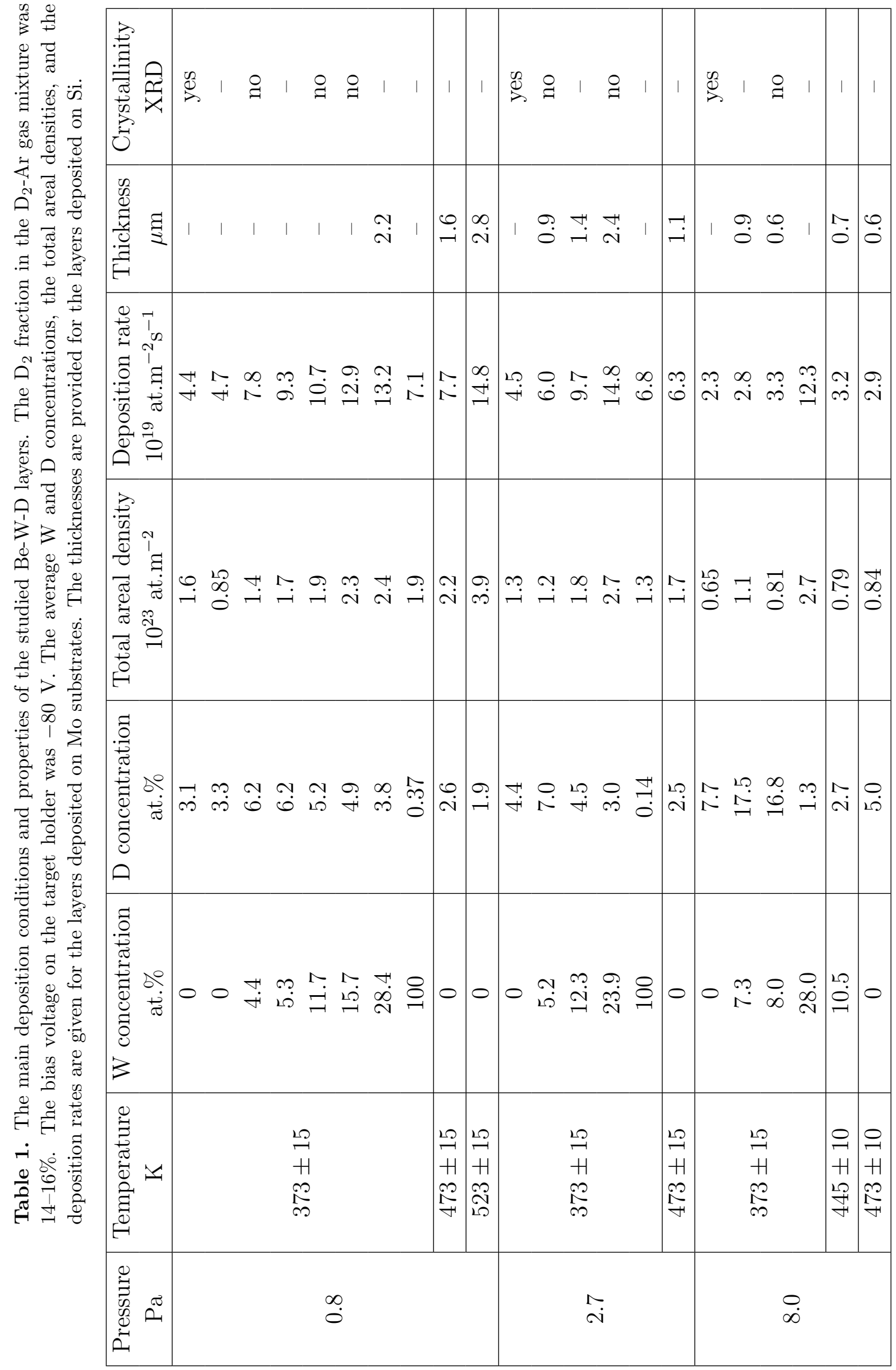




\subsection{Layer analyses}

The composition of the layers was determined using simultaneously nuclear reaction analysis (NRA) and Rutherford backscattering spectrometry (RBS) with $1.2 \mathrm{MeV}$, $2.4 \mathrm{MeV}$, and $4.5 \mathrm{MeV}{ }^{3} \mathrm{He}$ ions at IPP. The measurements were carried out a few months after the deposition. RBS measurements were performed at a scattering angle of $165^{\circ}$ using a detector with a solid angle of $1.7 \mathrm{msr}$. NRA measurements were performed at a reaction angle of $135^{\circ}$ using a detector with a depletion depth of $2000 \mu \mathrm{m}$ and a solid angle of $21.9 \mathrm{msr}$. The detector has a parabolic slit for minimizing geometrical energy spread [32] and is covered with a stopper foil of $5 \mu \mathrm{m}$ nickel and $13 \mu \mathrm{m}$ Mylar in order to stop backscattered ${ }^{3} \mathrm{He}$ ions. The measured NRA and RBS spectra were analyzed using the SIMNRA 7 code [33]. All concentrations in the text are given in atomic percent.

The total areal densities of the layers and $\mathrm{W}$ concentrations were determined using RBS. D concentrations were determined using the $\mathrm{D}\left({ }^{3} \mathrm{He}, \mathrm{p}\right) \alpha$ reaction. The reported accuracy of the $\mathrm{D}\left({ }^{3} \mathrm{He}, \mathrm{p}\right) \alpha$ cross section data is $5 \%$ [34] and the statistical counting error of the spectra is below $2 \%$. The accuracy of the ion current measurement in the present IBA setup is about 3\%. The Ar concentration in the layers is below the RBS detection limit of about $1 \%$.

The $\mathrm{O}$ content in the layers was determined using the ${ }^{16} \mathrm{O}\left({ }^{3} \mathrm{He}, \mathrm{p}_{0}\right){ }^{18} \mathrm{~F}$ reaction at $2.4 \mathrm{MeV}$ with the cross section data from [35]. For thick layers the proton peak from the ${ }^{16} \mathrm{O}\left({ }^{3} \mathrm{He}, \mathrm{p}_{0}\right){ }^{18} \mathrm{~F}$ reaction overlapped with the peak from the ${ }^{9} \mathrm{Be}\left({ }^{3} \mathrm{He}, \mathrm{p}_{6}\right){ }^{11} \mathrm{~B}$ reaction; for thinner layers it was separated between the ${ }^{9} \mathrm{Be}\left({ }^{3} \mathrm{He}, \mathrm{p}_{6}\right){ }^{11} \mathrm{~B}$ and the ${ }^{9} \mathrm{Be}\left({ }^{3} \mathrm{He}, \mathrm{p}_{7}\right){ }^{11} \mathrm{~B}$ peaks. The signal background from the various ${ }^{9} \mathrm{Be}^{3} \mathrm{He}$ reactions cannot be simulated accurately, so a smooth curve representing the background signal was derived by using a [(n-1)2n3H,twice] median smoother [33] with a running window width of $n=25$ channels. The background signal had identical shape for all Be-containing samples, but its height scaled with the amount of Be. Due to this background signal, the accuracy for determining the amount of $\mathrm{O}$ is about $50 \%$. The resulting $\mathrm{O}$ concentration in the layers was typically $1-2 \%$. The $\mathrm{O}$ content at the sample surface was enhanced and compatible with the assumption of a layer of 50 to $200 \times 10^{19}$ at.m ${ }^{-2} \mathrm{BeO}$. In some cases also an enhanced $\mathrm{O}$ content was observed at the interface between the Mo substrate and the layer, the thickness here is compatible with a $\mathrm{BeO}$ (or $\mathrm{MoO}$ ) layer with a thickness of 250 to $350 \times 10^{19}$ at. $\mathrm{m}^{-2}$.

The $\mathrm{C}$ concentration in the Be-based layers could not be determined using the ${ }^{12} \mathrm{C}\left({ }^{3} \mathrm{He}, \mathrm{p}_{\mathrm{x}}\right){ }^{14} \mathrm{~N}$ reactions due to the overlap with the peaks from the ${ }^{9} \mathrm{Be}\left({ }^{3} \mathrm{He}, \mathrm{p}_{\mathrm{x}}\right){ }^{11} \mathrm{~B}$ reactions. Using the cross section data from [36], the $\mathrm{C}$ content in $\mathrm{W}-\mathrm{D}$ layers was determined to be about $10 \times 10^{19}$ at. $\mathrm{m}^{-2}$. A similar $\mathrm{C}$ content is expected in Becontaining layers.

Using the $\mathrm{W}$ concentration determined by RBS, the $\mathrm{D}$ and $\mathrm{O}$ concentrations determined by NRA, Be is assumed to be the remaining constituent. The Be concentration determined in this way results in up to $10 \%$ lower simulated proton peaks 
from the ${ }^{9} \mathrm{Be}\left({ }^{3} \mathrm{He}, \mathrm{p}_{\mathrm{x}}\right){ }^{11} \mathrm{~B}$ reactions than the experimental ones when using the cross section data from Provatas et al. [37]. Concurrently, the simulated proton peaks are up to $20 \%$ higher than the experimental ones when using the cross section data by Barradas et al. [38]. This demonstrates, that the available NRA cross section data for Be still have substantial uncertainties.

$\mathrm{D}$ trapping states in the layers were studied using thermal desorption spectroscopy (TDS). The measurements were carried out for layers deposited on Mo substrates a few days after the deposition. Different samples from the same deposition batch were used for IBA and TDS. A sample is located in a quartz tube evacuated to about $10^{-5} \mathrm{~Pa}$ and is heated using a halogen lamp tube furnace. An edge of the sample is pressed against the tip of a K-type thermocouple located in the center of the tube. The sample is heated linearly up to $1273 \mathrm{~K}$ with a ramp of around $0.3 \mathrm{~K} / \mathrm{s}$ using a feedback-control system. Partial pressures of desorbing species are monitored using a quadrupole mass-spectrometer (QMS). The QMS signal of $\mathrm{D}_{2}$ molecules is quantified after each measurement using a calibrated leak bottle with the stated accuracy of $4.6 \%$. Calibration factors for $\mathrm{D}_{2}$ and HD molecules are assumed to be the same. The total D retention is calculated as the sum of $\mathrm{D}_{2}$ and $\mathrm{HD}$ contributions. In most cases the HD contribution was within $15 \%$. The amount of $\mathrm{D}$ released in the form of $\mathrm{HDO}$ and $\mathrm{D}_{2} \mathrm{O}$ molecules is negligible.

The crystalline structure and the phases existing in the layers were studied with Xray diffraction (XRD). A Bruker D8 Advance diffractometer with $\mathrm{Cu} \mathrm{K} \alpha$ radiation was used. To increase the layer's contribution to the diffraction pattern, the measurements were carried out at a fixed grazing X-ray incidence angle of $5^{\circ}$. The $2 \theta$ scans were performed in the range of $10-100^{\circ}$. The crystalline phases are identified using the ICSD database [39].

The microstructure of some layers was studied using scanning electron microscopy (SEM). The layer thicknesses were determined by examining fracture cross sections of the layers deposited on Si substrates. Several measurements at different locations were performed to get an average value. The resulting accuracy was about $0.1 \mu \mathrm{m}$.

Each specimen was weighed (with an accuracy of $10 \mu \mathrm{g}$ ) three times before and after the deposition to determine the layer mass. This was used to assess the similarity of the layers deposited in the same batch.

\section{Results}

\subsection{Layer composition and homogeneity}

Fig. 1 shows an example of concentration profiles of different elements in a layer determined by IBA. Except for the thin surface oxide, homogeneity of the composition with depth is within $15 \%$ for all layers. Inhomogeneity is more pronounced for the layers with low $\mathrm{W}$ concentrations and can be related to the stability of the $\mathrm{W}$ sputter source operation at low power. Average D and W concentrations in each layer are given 
in Table 1. The lateral homogeneity was checked by IBA for the layers deposited at $0.8 \mathrm{~Pa}$ and demonstrated excellent results. Similarity of the layers deposited on Mo and Si substrates was checked by IBA for the depositions at $0.8 \mathrm{~Pa}$ and showed very close compositions. Later in the text, only the data for the layers deposited on Mo substrates will be shown.

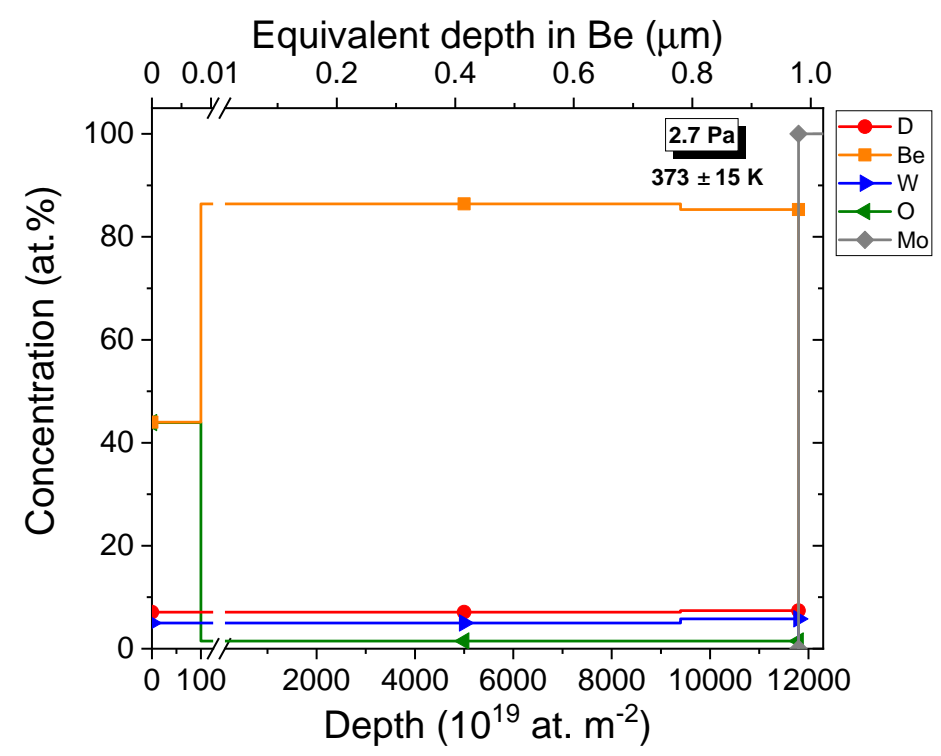

Figure 1. Concentration profiles of various elements in a Be-5.2\%W-D layer on Mo deposited at a pressure of $2.7 \mathrm{~Pa}$ and a sample temperature of $373 \pm 15 \mathrm{~K}$. The top $x$-axis shows the corresponding depth scale for bulk Be.

The D retention in the samples determined by NRA was systematically lower than that determined by TDS ranging from $4 \%$ to $50 \%$ for most of the samples; in one sample it was as high as $90 \%$. The coefficient of variation of masses of the layers from the same deposition batch used for NRA and TDS analyses is within 14\%. In fact, the highest variation is observed for the layers with low masses (Be-D) and is partially related with the accuracy of weighing. NRA demonstrates that the D concentration in Mo substrates is below $10^{-2} \%$. Therefore, D release during TDS is expected to originate predominantly from the layers. Two layers from the same batch have been measured by TDS with a time difference of a few days and the measured retention agreed within $6 \%$. This test has been made for two deposition batches. Concurrently, NRA gave about $25 \%$ smaller $\mathrm{D}$ retention than TDS for these two batches. Unfortunately, it was not possible to perform TDS measurements of a sample after NRA analysis. Therefore, the observed discrepancy between NRA and TDS may be caused by the uncertainties of the two methods, long-term D outgassing from the layers, and possibly some other uncontrolled factors. In a recent IAEA TDS Round Robin experiments such large discrepancies already have been observed [40]. We assume that the NRA data is more reliable and only the $\mathrm{D}$ concentrations determined by NRA are given in Table 1 . 


\subsection{Layer microstructure}

For the depositions at 2.7 Pa, the layers on Si and Mo substrates from the same batches have been measured by XRD and showed the same results. Since diffraction peaks from W and Mo can overlap, the XRD patterns of the layers deposited on Si substrates will be demonstrated. As an example, Fig. 2 shows XRD patterns of the layers deposited at $2.7 \mathrm{~Pa}$. The Be-D layer exhibits a strong orientation texture corresponding to the (002) reflection. In the case of a Be-W-D layer with $5.2 \% \mathrm{~W}$, two broad bumps near $20^{\circ}$ and $45^{\circ}$ are present. In a layer containing $23.9 \% \mathrm{~W}$, asymmetric and very broad peaks with maxima near $43^{\circ}$ and $66^{\circ}$ are visible. The presence of very broad peaks (bumps) is a typical sign of amorphous (or nanocrystalline) nature of the layers [41]. Similar tendencies were observed for the layers deposited at $0.8 \mathrm{~Pa}$ and $8 \mathrm{~Pa}$, see Table 1 . W-D layers could not be measured by XRD due to their poor adhesion to Si substrates.

SEM investigations of layer surfaces and their cross sections did not reveal any specific microstructure. As an example, Fig. 3 shows SEM images of the cross sections of various layers deposited at 2.7 Pa.

\subsection{Deuterium retention and thermal release}

Fig. 4 shows the $\mathrm{D}$ concentration in the layers deposited at $373 \mathrm{~K}$ and various gas pressures as a function of $\mathrm{W}$ concentration. Firstly, the $\mathrm{D}$ concentration in Be-D layers increases by a factor of 2.4 with increasing gas pressure from $0.8 \mathrm{~Pa}$ to $8 \mathrm{~Pa}$. Secondly, the dependences on $\mathrm{W}$ concentration are non-monotonic with a maximum at $4.4-7.3 \% \mathrm{~W}$. The corresponding maximal increase of the $\mathrm{D}$ concentration in Be-W-D layers as compared with Be-D layers is 1.6-2.3 times. At higher W concentrations, the $\mathrm{D}$ concentration decreases with increasing $\mathrm{W}$ concentration more rapidly at higher pressures. Finally, the D concentration in W-D layers is more than one order of magnitude smaller compared with that in Be-D layers. The latter result is in line with the previous observations [10]. The $\mathrm{D}$ concentration in Be-D and W-D layers deposited at $0.8 \mathrm{~Pa}$ is in reasonable agreement with that reported by Baldwin et al. [13, 17] for similar deposition conditions. The difference between the data sets mainly stems from the use of different methods for the $\mathrm{D}$ concentration determination (NRA vs. TDS, also see section 3.1) and from slightly different temperature windows during the layer deposition ( $\pm 15 \mathrm{~K}$ vs. $\pm 20 \mathrm{~K})$.

Fig. 5 shows the TDS spectra from the layers with various W concentrations deposited at a sample temperature of $373 \mathrm{~K}$ and various pressures. To account for different layer thicknesses, each TDS spectrum is normalized by the areal density of a layer from the same deposition batch as determined by IBA (see Table 1). It should also be kept in mind that increasing layer thickness typically shifts the desorption maximum towards higher temperatures [12, 16, 17].

In the case of deposition at $0.8 \mathrm{~Pa}$ (Fig. 5(a)), a Be-D layer exhibits a single desorption peak near $700 \mathrm{~K}$. Addition of $4.4-11.7 \% \mathrm{~W}$ gives rise to a large peak near $600 \mathrm{~K}$, a shoulder near $500 \mathrm{~K}$, and a small peak near $450 \mathrm{~K}$; the amplitude of the $700 \mathrm{~K}$ 


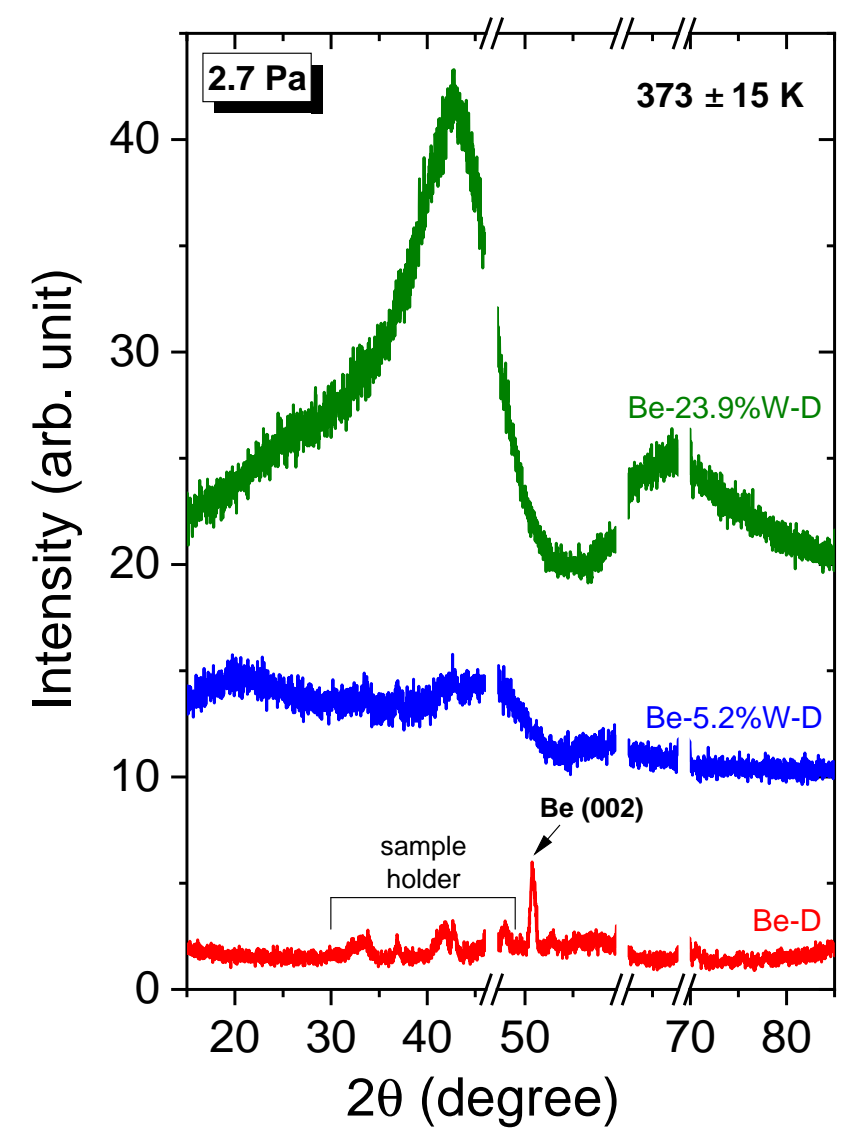

Figure 2. XRD patterns of Be-W-D layers on Si (100) deposited at a pressure of $2.7 \mathrm{~Pa}$ and a sample temperature of $373 \pm 15 \mathrm{~K}$. The breaks on the $x$-axis are to hide artifacts due to the sample holder and a strong $\mathrm{Si}$ (004) reflection. The $y$-axis is shifted for each spectrum. Note that the increase of the signal with increasing W concentration is due to the much higher X-ray scattering cross-section of $\mathrm{W}$ compared to Be.
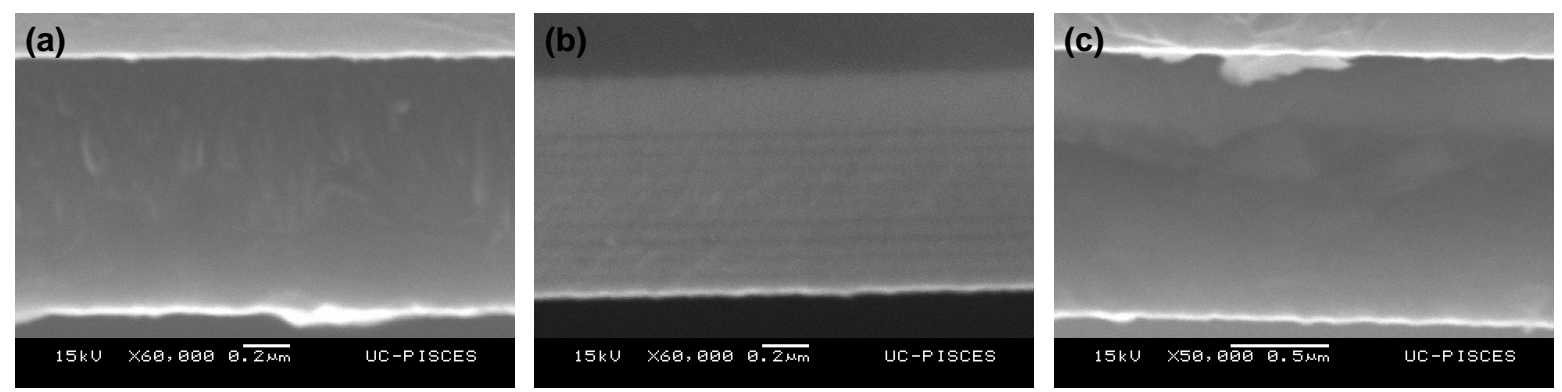

Figure 3. SEM images of the the cross sections of layers on Si (100) deposited at a pressure of $2.7 \mathrm{~Pa}$ : (a) Be-D deposited at of $473 \pm 15 \mathrm{~K}$; (b) Be- $5.2 \% \mathrm{~W}-\mathrm{D}$ deposited at $373 \pm 15 \mathrm{~K}$; (c) Be-12.3\%W-D deposited at $373 \pm 15 \mathrm{~K}$. The Si substrate is located at the top of the figures. Note the different magnification in (c).

peak also increases. Concurrently, in the layers containing $15.7 \%$ and $28.4 \% \mathrm{~W}$ these 


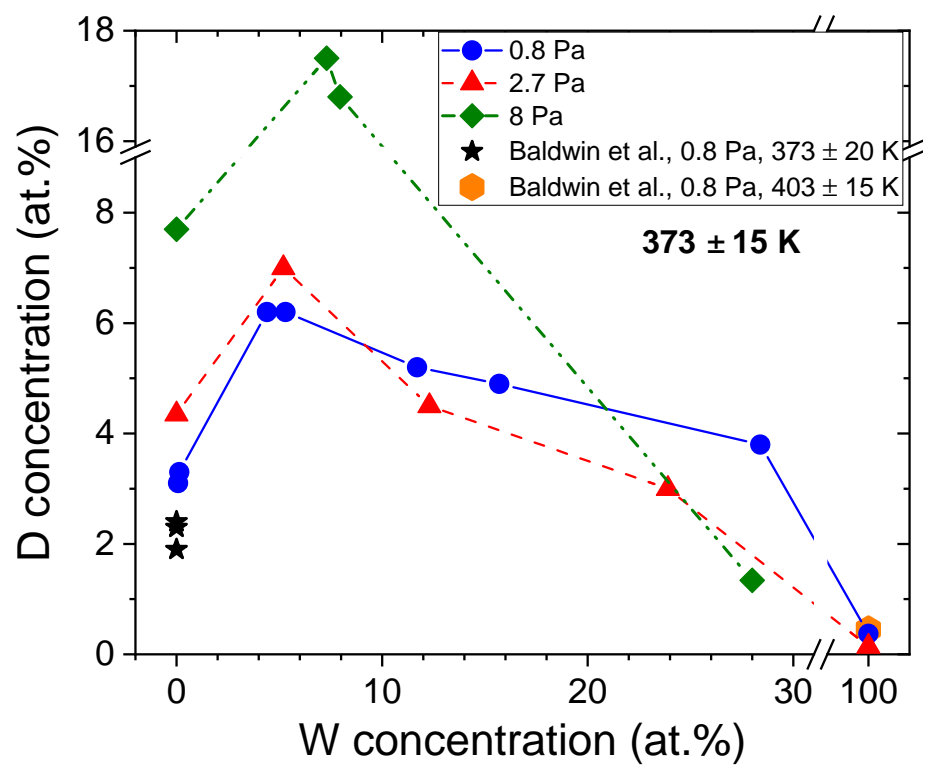

Figure 4. D concentration in Be-W-D layers on Mo as a function of W concentration for various gas pressures during deposition. The layers were deposited at a sample temperature of $373 \pm 15 \mathrm{~K}$. The data reported by Baldwin et al. 13, 17 for Be-D layers and W-D layers deposited at $0.8 \mathrm{~Pa}$ and sample temperatures of $373 \pm 20 \mathrm{~K}$ and $403 \pm 15 \mathrm{~K}$, respectively, is also shown. Displayed lines are guidelines for the eye only.

low-temperature peaks are absent and the position of the main desorption peak shifts towards higher temperatures with increasing $\mathrm{W}$ concentration. The TDS spectrum from a W-D layer (not shown) exhibits a single broad desorption peak near $600 \mathrm{~K}$, similar to that observed by Baldwin et al. [17].

Increase of the pressure to 2.7 Pa (Fig. 5(b)) transforms the peak near $450 \mathrm{~K}$ and the shoulder near $500 \mathrm{~K}$ into sharp peaks in the TDS spectrum from a Be-D layer. The addition of $5.2 \% \mathrm{~W}$ results in an increase of their amplitudes, with a stronger effect on the $500 \mathrm{~K}$ peak. Moreover, the amplitude of the shoulder near $600 \mathrm{~K}$ also increases. For higher $\mathrm{W}$ concentrations of $12.3 \%$ and $23.9 \% \mathrm{~W}$, the $500 \mathrm{~K}$ peak disappears and the amplitude of the $450 \mathrm{~K}$ peak also considerably decreases. Similarly to the results at $0.8 \mathrm{~Pa}$, a shift of the $\mathrm{D}$ release towards higher temperatures with increasing $\mathrm{W}$ concentration is visible. The TDS spectrum from a W-D layer (not shown) looks similar to that obtained at $0.8 \mathrm{~Pa}$, albeit the $\mathrm{D}$ retention is lower.

At the highest used pressure of $8 \mathrm{~Pa}$ (Fig. 5(c)), the TDS spectrum from a Be-D codeposit is similar to that at $2.7 \mathrm{~Pa}$, although the splitting of two sharp peaks is less pronounced. Addition of 7.3-8.0\% W results in a very strong increase of the amplitude of the $450 \mathrm{~K}$ peak. Concurrently, the amplitude of the second sharp peak near $500 \mathrm{~K}$ does not change significantly. The $700 \mathrm{~K}$ peak is almost absent in the spectra of these layers. In the layer containing $28 \% \mathrm{~W}$, the sharp desorption peaks are absent. In contrast with the layers deposited at lower pressures, no shift of the desorption maximum towards higher temperatures is visible. 


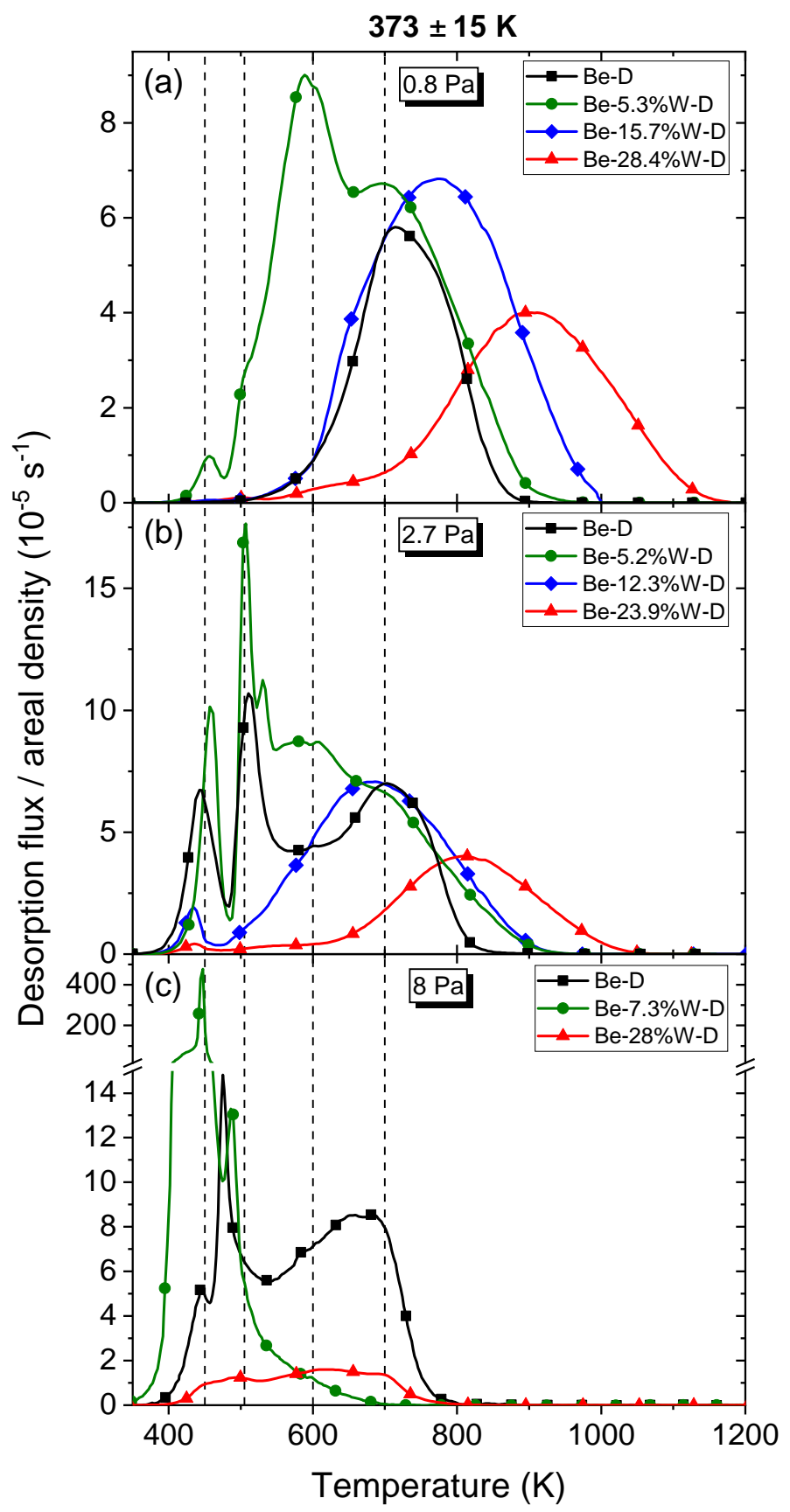

Figure 5. TDS spectra of $\mathrm{D}_{2}$ molecules from $\mathrm{Be}-\mathrm{W}-\mathrm{D}$ layers on Mo with various $\mathrm{W}$ concentrations deposited at (a) $0.8 \mathrm{~Pa}$, (b) $2.7 \mathrm{~Pa}$, and (c) $8 \mathrm{~Pa}$. The layers were deposited at a sample temperature of $373 \pm 15 \mathrm{~K}$. Each spectrum is normalized by the areal density of the layer from the same deposition batch as determined by IBA. Note that (a), (b), and (c) have different $y$-scales. Dashed lines indicate approximate position of the desorption peaks discussed in the text.

The influence of deposition temperature on the $\mathrm{D}$ retention in the layers has been examined mainly for Be-D layers (Fig. 6). In the case of layers deposited at $0.8 \mathrm{~Pa}$, the decrease of the $\mathrm{D}$ concentration with increasing deposition temperature is rather 


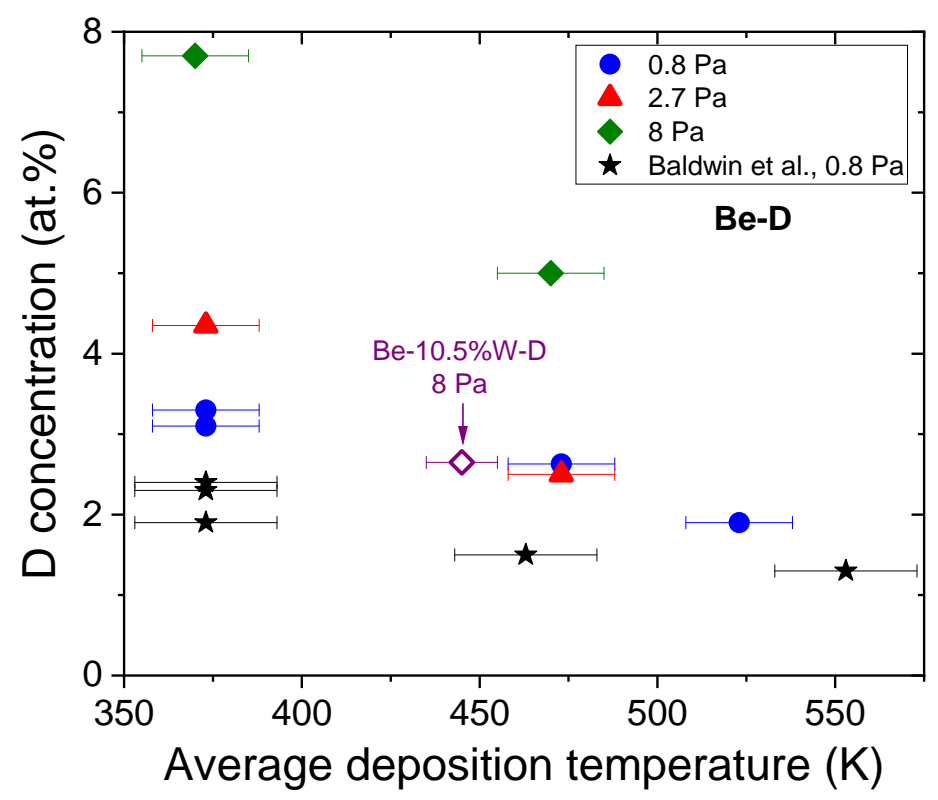

Figure 6. D concentration in Be-D layers on Mo as a function of deposition temperature for various gas pressures. The data for a Be-10.5\%W-D layer deposited at $8 \mathrm{~Pa}$ and a temperature of $445 \pm 10 \mathrm{~K}$ is also shown. The data reported by Baldwin et al. 13] for Be-D layers deposited at $0.8 \mathrm{~Pa}$ is also demonstrated.

small within the investigated range, in agreement with Baldwin et al. [13]. This can be explained by the fact that the $\mathrm{D}$ desorption maximum from all these layers is located at 700-800 K (see Figs. 5(a) and 7), which is well below the maximum used deposition temperature. With increasing gas pressure, the temperature dependence of the $\mathrm{D}$ retention in the layers becomes more pronounced. The sharp low-temperature peaks are absent in the TDS spectra from the layers deposited at $473 \mathrm{~K}$ and pressures of $2.7 \mathrm{~Pa}$ and $8 \mathrm{~Pa}$ : Compare Fig. 7 with Figs. 5 (b) and (c). This demonstrates that the corresponding trapping sites are not populated with $\mathrm{D}$ (or even not created) during the deposition at $473 \mathrm{~K}$. Although the TDS spectra from all layers deposited at $473 \mathrm{~K}$ have close positions of the desorption maximum, its amplitude increases with increasing pressure. This can also be seen in the spectra from the layers deposited at $373 \mathrm{~K}$. This means that the concentration of the trapping sites corresponding to the TDS peak near $700 \mathrm{~K}$ also increases with increasing gas pressure during the deposition.

Since the largest effect of deposition temperature variation has been observed for the layers deposited at $8 \mathrm{~Pa}$, a Be-W-D layer containing $10.5 \% \mathrm{~W}$ (close to the maximum in Fig. (4) has been deposited at this pressure. Due to operation at low power on the $\mathrm{W}$ sputter gun, the sample temperature during the deposition was only $445 \pm 10 \mathrm{~K}$. Interestingly, the $\mathrm{D}$ concentration in this layer is lower than in a Be-D layer deposited at $473 \mathrm{~K}$ and the same pressure (Fig. 6). This can be rationalized by looking at the TDS spectra of the layers deposited at $373 \mathrm{~K}$ (Fig. 5(c)) where the amplitudes of the peaks 


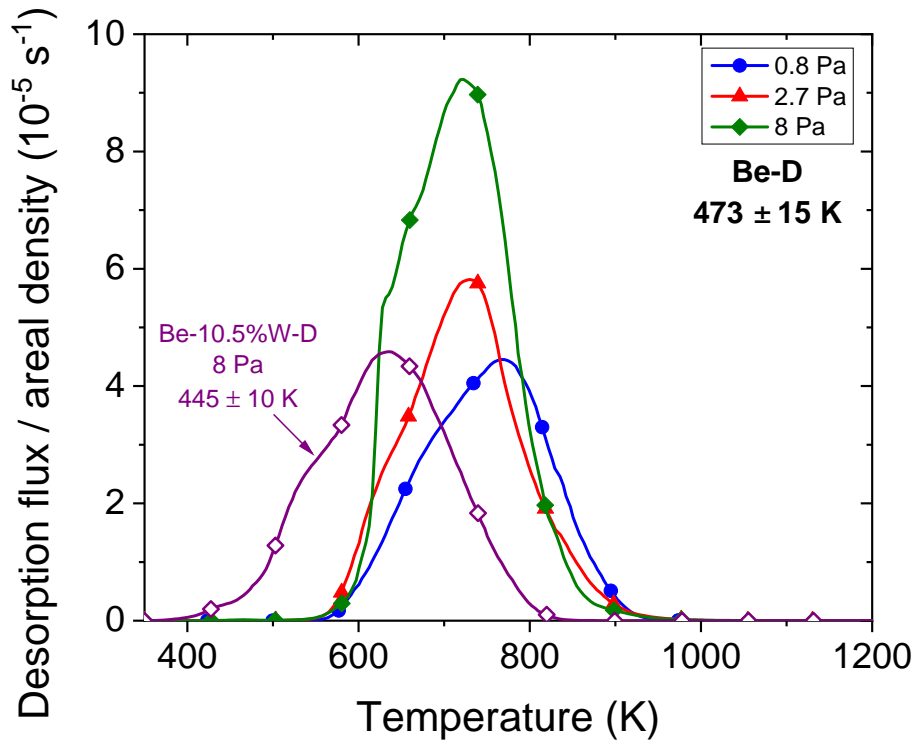

Figure 7. TDS spectra of $\mathrm{D}_{2}$ molecules from Be-D layers on Mo deposited at various gas pressures. The layers were deposited at a sample temperature of $473 \pm 15 \mathrm{~K}$. The spectrum from the Be-10.5\%W-D layer deposited at $8 \mathrm{~Pa}$ and a temperature of $445 \pm 10 \mathrm{~K}$ is also shown. Each spectrum is normalized by the areal density of the layer from the same deposition batch as determined by IBA.

(shoulders) near $600 \mathrm{~K}$ and $700 \mathrm{~K}$ from Be-W-D layers are considerably smaller than from a Be-D layer. The same is visible for the layers deposited at elevated temperatures (Fig. 7). Consequently, in the case of deposition at $8 \mathrm{~Pa}$ the corresponding trapping sites for $\mathrm{D}$ are formed less effectively in Be-W-D layers than in Be-D layers. The fact that the D release from a Be-W-D layer in Fig. 7 starts at lower temperatures than from Be-D layers can partially be due to the lower deposition temperature in the former case. However, the contribution of uncertainties related with the temperature measurement during the deposition and the TDS run cannot be ruled out.

\section{Discussion}

It is well known that the D retention in both bulk Be and $\mathrm{W}$ is governed by trapping in lattice defects [5, 7]. In Be, the formation of deuteride is considered to play an important role [42, 43]. It can be assumed that the same holds for codeposited layers. Therefore, $\mathrm{D}$ retention in codeposited layers should be intimately linked with their microstructure. Furthermore, since D is implanted in layers during their growth, D trapping in them is also influenced by incident $\mathrm{D}$ ion energy, D ion flux, deposition rate, and substrate temperature [10, 44].

Within a single experimental series in this study, the substrate temperature and the incident ion energy were kept close. However, the deposition rate increased up to a factor of 5.3 with increasing power on the $\mathrm{W}$ sputter gun, i.e., $\mathrm{W}$ concentration in a layer, see Table 1. Furthermore, increasing power on the W gun also increases the 
plasma density, which increases the ion flux. Increase of the current on the substrate holder up to a factor of two has been observed. Lastly, the layer composition also affects the D ion penetration. Simulations in SDTrimSP 5.07 [45] of $40 \mathrm{eV} / \mathrm{D}$ ions incident on $\mathrm{Be}-\mathrm{W}$ targets indicate that the ion range does not significantly change with increasing $\mathrm{W}$ concentration from $0 \%$ to $28 \%$ while the reflection coefficient increases by a factor of two. Since all these dependences are monotonic, it is unlikely that their variations cause the observed maximum in the $\mathrm{D}$ concentration in Be-W-D layers with 4.4-7.3\% $\mathrm{W}$. Therefore, it has to be concluded that the addition of $4.4-7.3 \% \mathrm{~W}$ to a Be layer introduces additional trapping sites for D. The TDS results indicate that these trapping sites mainly correspond to three low-temperature (up to $600 \mathrm{~K}$ ) D release peaks. The relative contributions of the trapping sites corresponding to each peak strongly depend on gas pressure during deposition.

It is well known that the layer microstructure is influenced by gas pressure and substrate temperature during deposition [31, 46]. Gas pressure affects the transport of sputtered atoms to a substrate: The higher the pressure is, the greater is the number of collisions of sputtered atoms with gas atoms, which reduces their energy and directionality. Reduction of the energy of sputtered atoms arriving onto a substrate reduces adatom mobility, favoring formation of a porous microstructure. Furthermore, the energy of the ions accelerated in the sheath in front of a substrate, as well as of energetic neutral atoms reflected from sputter targets, also decrease with increasing pressure. This can also affect the layer microstructure as bombardment with energetic species tends to densify a growing layer. These factors may explain the observed increase in $\mathrm{D}$ trapping with increasing pressure during deposition.

The appearance of the sharp low-temperature $\mathrm{D}$ release peak for the Be-D layers deposited at $2.7 \mathrm{~Pa}$ and $8 \mathrm{~Pa}$ is in agreement with the observations by Baldwin et al. 13]. Such a peak has also been observed in TDS spectra from bulk Be after keV D ion implantation above a critical fluence (around $10^{21} \mathrm{Dm}^{-2}$ ) [47, 48, 49, 50], as well as after exposure to low-energy D ions from a plasma [51, 52. The presence of two closely located sharp peaks (like in the present study) or a sharp peak and a shoulder has also been observed in some studies with bulk Be [47, 48, 49, 50, 51]. However, it has never been observed for codeposited layers. The nature of the trapping sites corresponding to these sharp peaks is still not clear and the corresponding discussions can be found elsewhere [48, 53, 54]. Nevertheless, it appears that the addition of $4.4-7.3 \% \mathrm{~W}$ increases the concentration of these trapping sites in codeposited layers.

It is interesting to mention that Sugiyama et al. [23] observed several times lower $\mathrm{D}$ concentration in a Be-6\% W layer compared with that in a pure Be layer. However, in their experiment $\mathrm{D}$ was implanted into the layers after their deposition (by thermionic vacuum arc), while in the present work $\mathrm{D}$ was codeposited together with $\mathrm{Be}$ and $\mathrm{W}$ atoms. This could have affected the layer microstructure and the D trapping. 


\section{Conclusion}

The aim of this work was to assess the effect of the presence of small amounts of $\mathrm{W}$ $(<30 \%)$ in Be layers on the efficiency of D trapping and thermal release. The layers were mostly deposited at a substrate temperature near $373 \mathrm{~K}$, which is the minimal temperature of $\mathrm{W}$ components in ITER where the formation of codeposited layers can occur. The gas pressure during deposition varied in the range of $0.8-8 \mathrm{~Pa}$ to cover the divertor neutral pressure range in ITER. It was found that addition of a rather small amount of $\mathrm{W}(4.4-7.3 \%)$ increases the trapped $\mathrm{D}$ concentration by a factor of two as compared with a Be-D layer. Increase of gas pressure during deposition was found to increase D trapping both in these mixed layers, as well as in Be-D layers. Concurrently, at higher $\mathrm{W}$ concentrations the decrease of the $\mathrm{D}$ concentration with increasing $\mathrm{W}$ concentration occurs faster at higher pressures. It can be concluded that the enhanced D trapping in Be-W-D layers containing small amounts of $\mathrm{W}$ is linked to the introduction of additional D trapping sites corresponding to three low-temperature (up to $600 \mathrm{~K}$ ) D release peaks. Therefore, for the layers deposited at temperatures of $450 \mathrm{~K}$ and above, these trapping sites cannot hold considerable amounts of $\mathrm{D}$ and the effect of $\mathrm{W}$ addition on $\mathrm{D}$ trapping diminishes. However, the layers with higher W content (15.7-28.4\%) deposited at $0.8 \mathrm{~Pa}$ and $2.7 \mathrm{~Pa}$ demonstrated a shift of the $\mathrm{D}$ desorption maximum towards higher temperatures. This indicates that $\mathrm{D}$ removal by baking may be less efficient than that from Be-D and Be-W-D layers with low W content.

Collectively, the results may influence ITER bake efficiency and frequency requirements for $\mathrm{T}$ inventory control, should significant amounts of mixed layers form. The efficiency of $\mathrm{D}$ removal from Be-W-D layers by baking and laser-induced desorption needs to be addressed in a future work.

\section{Acknowledgements}

The help of the PISCES-B enclosure personnel is deeply appreciated. The technical assistance of J. Dorner and M. Fußeder from IPP Garching is also gratefully acknowledged. This work has been carried out as part of the US-EU Bilateral Collaboration on ITER Materials within the framework of the EUROfusion Consortium

and has received funding from the Euratom research and training programme 2014-2018 and 2019-2020 under grant agreement No 633053. The views and opinions expressed herein do not necessarily reflect those of the European Commission. This work has also been supported by the US Department of Energy grant No DE-FG02-07ER54912.

\section{References}

[1] M. Mayer, S. Krat, W. V. Renterghem, A. Baron-Wiechec, S. Brezinsek, I. Bykov, P. Coad, Y. Gasparyan, K. Heinola, J. Likonen, A. Pisarev, C. Ruset, G. de Saint-Aubin, A. Widdowson, 
JET Contributors, Erosion and deposition in the JET divertor during the first ILW campaign, Physica Scripta T167 (2016) 014051. doi:10.1088/0031-8949/t167/1/014051.

[2] M. Mayer, S. Krat, A. Baron-Wiechec, Y. Gasparyan, K. Heinola, S. Koivuranta, J. Likonen, C. Ruset, G. de Saint-Aubin, A. Widdowson, JET Contributors, Erosion and deposition in the JET divertor during the second ITER-like wall campaign, Physica Scripta T170 (2017) 014058. doi:10.1088/1402-4896/aa8ff9.

[3] A. Widdowson, J. Coad, E. Alves, A. Baron-Wiechec, N. Catarino, V. Corregidor, K. Heinola, S. Krat, C. Makepeace, G. Matthews, M. Mayer, K. Mizohata, M. Sertoli, Deposition of impurity metals during campaigns with the JET ITER-like Wall, Nuclear Materials and Energy 19 (2019) 218 - 224. doi:10.1016/j.nme.2018.12.024.

[4] A. Lahtinen, J. Likonen, S. Koivuranta, E. Alves, A. Baron-Wiechec, N. Catarino, J. Coad, K. Heinola, J. Räisänen, A. Widdowson, Deuterium retention on the tungsten-coated divertor tiles of JET ITER-like wall in 2015-2016 campaign, Fusion Engineering and Design 146 (2019) 1979 - 1982. doi:10.1016/j.fusengdes.2019.03.081.

[5] C. H. Skinner, A. A. Haasz, V. K. Alimov, N. Bekris, R. A. Causey, R. E. H. Clark, J. P. Coad, J. W. Davis, R. P. Doerner, M. Mayer, A. Pisarev, J. Roth, T. Tanabe, Recent advances on hydrogen retention in ITER's plasma-facing materials: Beryllium, carbon, and tungsten, Fusion Science and Technology 54 (2008) 891-945. doi:10.13182/FST54-891.

[6] J. Roth, E. Tsitrone, A. Loarte, T. Loarer, G. Counsell, R. Neu, V. Philipps, S. Brezinsek, M. Lehnen, P. Coad, C. Grisolia, K. Schmid, K. Krieger, A. Kallenbach, B. Lipschultz, R. Doerner, R. Causey, V. Alimov, W. Shu, O. Ogorodnikova, A. Kirschner, G. Federici, A. Kukushkin, Recent analysis of key plasma wall interactions issues for ITER, Journal of Nuclear Materials 390-391 (2009) 1 - 9. doi:10.1016/j.jnucmat.2009.01.037.

[7] G. Federici, R. Doerner, P. Lorenzetto, V. Barabash, 4.19 - Beryllium as a Plasma-Facing Material for Near-Term Fusion Devices, in: Comprehensive Nuclear Materials, R.J.M. Konings (Ed.), Elsevier, Oxford, 2012. doi:10.1016/B978-0-08-056033-5.00121-X.

[8] A. Widdowson, J. Coad, E. Alves, A. Baron-Wiechec, N. Barradas, S. Brezinsek, N. Catarino, V. Corregidor, K. Heinola, S. Koivuranta, S. Krat, A. Lahtinen, J. Likonen, G. Matthews, M. Mayer, P. Petersson, M. R. and, Overview of fuel inventory in JET with the ITER-like wall, Nuclear Fusion 57 (2017) 086045. doi:10.1088/1741-4326/aa7475.

[9] A. Khan, G. De Temmerman, S. Lisgo, X. Bonnin, H. Anand, M. Miller, R. Pitts, K. Schmid, A. Kukushkin, WallDYN simulations of material migration and fuel retention in ITER low power $\mathrm{H}$ plasmas and high power neon-seeded DT plasmas, Nuclear Materials and Energy 20 (2019) 100674. doi:10.1016/j.nme.2019.100674

[10] R. Doerner, M. Baldwin, G. De Temmerman, J. Hanna, D. Nishijima, J. Roth, K. Schmid, G. Tynan, K. Umstadter, Codeposition of deuterium with ITER materials, Nuclear Fusion 49 (2009) 035002. doi:10.1088/0029-5515/49/3/035002.

[11] M. Baldwin, T. Schwarz-Selinger, R. Doerner, Experimental study and modelling of deuterium thermal release from Be-D co-deposited layers, Nuclear Fusion 54 (2014) 073005. doi:10. 1088/0029-5515/54/7/073005.

[12] M. Baldwin, R. Doerner, Effect of layer thickness on the thermal release from Be-D co-deposited layers, Nuclear Fusion 54 (2014) 083032. doi:10.1088/0029-5515/54/8/083032.

[13] M. J. Baldwin, M. J. Simmonds, G. De Temmerman, R. P. Doerner, Deuterium retention in Be-D co-deposits formed over an ITER relevant parameter space, Physica Scripta T171 (2020) 014014. doi:10.1088/1402-4896/ab41a3.

[14] A. Hakola, K. Heinola, K. Mizohata, J. Likonen, C. Lungu, C. Porosnicu, E. Alves, R. Mateus, I. B. Radovic, Z. Siketic, V. Nemanic, M. Kumar, C. Pardanaud, P. Roubin, EUROfusion WP PFC Contributors, Effect of composition and surface characteristics on fuel retention in berylliumcontaining co-deposited layers, Physica Scripta T171 (2020) 014038. doi:10.1088/1402-4896/ ab4be8.

[15] S. Krat, Y. Gasparyan, Y. Vasina, A. Davletiyarova, A. Pisarev, Tungsten-deuterium co-deposition: 
Experiment and analytical description, Vacuum 149 (2018) 23 - 28. doi:10.1016/j.vacuum. 2017.12 .004

[16] L. Qiao, H. Zhang, J. Xu, L. Chai, M. Hu, P. Wang, Deuterium retention and release behaviours of tungsten and deuterium co-deposited layers, Journal of Nuclear Materials 502 (2018) 247 254. doi:10.1016/j.jnucmat.2018.02.009

[17] M. Baldwin, A. Založnik, R. Smirnov, R. Doerner, Experimental measurements and modeling of the deuterium release from tungsten co-deposited layers, Nuclear Materials and Energy 23 (2020) 100743. doi:10.1016/j.nme.2020.100743

[18] A. Založnik, M. J. Baldwin, R. P. Doerner, T. Schwarz-Selinger, S. Brezinsek, The influence of helium on deuterium retention in beryllium co-deposits, Journal of Nuclear Materials 512 (2018) 25 - 30. doi:10.1016/j.jnucmat.2018.09.032.

[19] T. Dittmar, M. Baldwin, R. Doerner, D. Nishijima, T. Schwarz-Selinger, Deuterium retention in Be:N:D codeposits, Journal of Nuclear Materials 438 (2013) S988 - S991. doi:10.1016/j. jnucmat.2013.01.215.

[20] P. Dinca, B. Butoi, C. Porosnicu, O. G. Pompilian, C. Staicu, C. P. Lungu, I. Burducea, Structure, morphology and deuterium retention and release properties of pure and mixed Be and $\mathrm{W}$ layers, Journal of Physics D: Applied Physics 53 (32) (2020) 325304. doi:10.1088/1361-6463/ab88e7.

[21] I. Jepu, R. Doerner, M. Baldwin, C. Porosnicu, C. Lungu, Temperature influence on deuterium retention for $\mathrm{Be}-\mathrm{W}$ mixed thin films prepared by Thermionic Vacuum Arc method exposed to PISCES B plasma, Journal of Nuclear Materials 463 (2015) 983 - 988. doi:10.1016/j. jnucmat.2014.10.029.

[22] R. Mateus, A. Hakola, V. Tiron, C. Porosnicu, C. Lungu, E. Alves, Study of deuterium retention in Be-W coatings with distinct roughness profiles, Fusion Engineering and Design 124 (2017) 464 - 467. doi:10.1016/j.fusengdes.2017.01.018.

[23] K. Sugiyama, C. Porosnicu, W. Jacob, I. Jepu, C. Lungu, Investigation of deuterium retention in/desorption from beryllium-containing mixed layers, Nuclear Materials and Energy 6 (2016) 1 - 9. doi:10.1016/j.nme.2015.08.001.

[24] P. Dinca, C. Porosnicu, B. Butoi, I. Jepu, V. Tiron, O. Pompilian, I. Burducea, C. Lungu, I.-L. Velicu, Beryllium-tungsten study on mixed layers obtained by m-HiPIMS/DCMS techniques in a deuterium and nitrogen reactive gas mixture, Surface and Coatings Technology 321 (2017) 397 - 402. doi:10.1016/j.surfcoat.2017.04.074.

[25] G. De Temmerman, M. Baldwin, D. Anthoine, K. Heinola, A. Jan, I. Jepu, J. Likonen, C. Lungu, C. Porosnicu, R. Pitts, Efficiency of thermal outgassing for tritium retention measurement and removal in ITER, Nuclear Materials and Energy 12 (2017) 267 - 272. doi:10.1016/j.nme. 2016.10 .016

[26] R. Pitts, X. Bonnin, F. Escourbiac, H. Frerichs, J. Gunn, T. Hirai, A. Kukushkin, E. Kaveeva, M. Miller, D. Moulton, V. Rozhansky, I. Senichenkov, E. Sytova, O. Schmitz, P. Stangeby, G. De Temmerman, I. Veselova, S. Wiesen, Physics basis for the first ITER tungsten divertor, Nuclear Materials and Energy 20 (2019) 100696. doi:10.1016/j.nme.2019.100696

[27] M. A. Lieberman, A. J. Lichtenberg, Principles of Plasma Discharges and Materials Processing, John Wiley \& Sons, Ltd, 2005. doi:10.1002/0471724254.

[28] P. Saikia, B. Kakati, B. K. Saikia, Study on the effect of target on plasma parameters of magnetron sputtering discharge plasma, Physics of Plasmas 20 (10) (2013) 103505. doi: $10.1063 / 1.4825235$

[29] M. Sode, T. Schwarz-Selinger, W. Jacob, Ion chemistry in $\mathrm{H}_{2}$-Ar low temperature plasmas, Journal of Applied Physics 114 (6) (2013) 063302. doi:10.1063/1.4817526.

[30] M. Jiménez-Redondo, M. Cueto, J. L. Doménech, I. Tanarro, V. J. Herrero, Ion kinetics in $\mathrm{Ar} / \mathrm{H}_{2}$ cold plasmas: the relevance of $\mathrm{ArH}^{+}$, RSC Advances 4 (2014) 62030-62041. doi: 10.1039/C4RA13102A.

[31] D. Depla, S. Mahieu, J. Greene, Chapter 5 - sputter deposition processes, in: P. M. Martin (Ed.), Handbook of Deposition Technologies for Films and Coatings (Third Edition), William Andrew 
Publishing, Boston, 2010, pp. 253 - 296. doi:10.1016/B978-0-8155-2031-3.00005-3.

[32] M. Mayer, E. Gauthier, K. Sugiyama, U. von Toussaint, Quantitative depth profiling of deuterium up to very large depths, Nuclear Instruments and Methods in Physics Research Section B 267 (2009) 506 - 512. doi:10.1016/j.nimb.2008.11.033.

[33] M. Mayer, SIMNRA user's guide for version 7, Tech. Rep. IPP 9/113, Max-Planck-Institut für Plasmaphysik, Garching, Germany (2018). URL http://home.mpcdf .mpg.de/ mam/Report\%20IPP\%209-113.pdf

[34] B. Wielunska, M. Mayer, T. Schwarz-Selinger, U. von Toussaint, J. Bauer, Cross section data for the $\mathrm{D}\left({ }^{3} \mathrm{He}, \mathrm{p}\right)^{4} \mathrm{He}$ nuclear reaction from 0.25 to $6 \mathrm{MeV}$, Nuclear Instruments and Methods in Physics Research Section B 371 (2016) 41 - 45. doi:10.1016/j.nimb.2015.09.049.

[35] M. Guitart Corominas, T. Schwarz-Selinger, Experimental determination of the ${ }^{16} \mathrm{O}\left({ }^{3} \mathrm{He}, \mathrm{p}_{0}\right){ }^{18} \mathrm{~F}$ differential cross section, Nuclear Instruments and Methods in Physics Research Section B 450 (2019) 13 - 18. doi:10.1016/j.nimb.2018.05.018.

[36] R. L. Johnston, H. D. Holmgren, E. A. Wolicki, E. G. Illsley, Differential cross sections for the $\mathrm{C}^{12}\left(\mathrm{He}^{3}, p\right) \mathrm{N}^{14}$ reaction, Phys. Rev. 109 (1958) 884-887. doi:10.1103/PhysRev.109.884

[37] G. Provatas, S. Fazinić, N. Soić, N. Vukman, D. Cosic, M. Krmpotić, M. Vukšić, A. Crnjac, R. Popočovski, L. Palada, P. Čolović, D. Dell'Aquila, I. Gašparić, D. J. Malenica, T. Mijatović, M. Uroić, Differential cross section measurements of the ${ }^{9} \mathrm{Be}\left({ }^{3} \mathrm{He}, \mathrm{p}\right){ }^{11} \mathrm{~B}$ reaction for NRA applications, Nuclear Instruments and Methods in Physics Research Section B 472 (2020) 36 45. doi:10.1016/j.nimb.2020.03.039.

[38] N. Barradas, N. Catarino, R. Mateus, S. Magalhães, E. Alves, Z. Siketić, I. B. Radović, Determination of the ${ }^{9} \mathrm{Be}\left({ }^{3} \mathrm{He}, \mathrm{p}_{\mathrm{i}}\right){ }^{11} \mathrm{~B}(\mathrm{i}=0,1,2,3)$ cross section at $135^{\circ}$ in the energy range $1-2.5$ $\mathrm{MeV}$, Nuclear Instruments and Methods in Physics Research Section B 346 (2015) 21 - 25. doi:10.1016/j.nimb.2015.01.037.

[39] https://icsd.fiz-karlsruhe.de/. URL https://icsd.fiz-karlsruhe.de/

[40] https://www-amdis.iaea.org/crp/irradiatedtungsten/rcm3/. URL https://www-amdis .iaea.org/CRP/IrradiatedTungsten/RCM3/

[41] M. Birkholz, Identification of Chemical Phases, in: Thin Film Analysis by X-Ray Scattering, John Wiley \& Sons, Ltd, 2006. doi:10.1002/3527607595.ch2.

[42] R. Doerner, M. Baldwin, D. Buchenauer, G. De Temmerman, D. Nishijima, The role of beryllium deuteride in plasma-beryllium interactions, Journal of Nuclear Materials 390-391 (2009) 681 684. doi:10.1016/j.jnucmat.2009.01.187.

[43] C. Pardanaud, M. I. Rusu, C. Martin, G. Giacometti, P. Roubin, Y. Ferro, A. Allouche, M. Oberkofler, M. Köppen, T. Dittmar, C. Linsmeier, Hydrogen retention in beryllium: concentration effect and nanocrystalline growth, Journal of Physics: Condensed Matter 27 (47) (2015) 475401. doi:10.1088/0953-8984/27/47/475401.

[44] S. Krat, A. Prishvitsyn, Y. Vasina, Y. Gasparyan, A. Pisarev, Model for hydrogen accumulation in co-deposited layers, Nuclear Materials and Energy 24 (2020) 100763. doi:10.1016/j.nme. 2020.100763

[45] A. Mutzke, R. Schneider, W. Eckstein, R. Dohmen, SDTrimSP Version 5.00, Tech. Rep. IPP 12/8, Max-Planck-Institut für Plasmaphysik, Garching, Germany (2011). URL http://hdl . handle.net/11858/00-001M-0000-0026-EAF9-A

[46] S. Mahieu, P. Ghekiere, D. Depla, R. D. Gryse, Biaxial alignment in sputter deposited thin films, Thin Solid Films 515 (4) (2006) 1229 - 1249. doi:10.1016/j.tsf.2006.06.027.

[47] A. V. Markin, V. N. Chernikov, S. Y. Rybakov, A. P. Zakharov, Thermal desorption of deuterium implanted into beryllium, Journal of Nuclear Materials 233-237 (1996) 865 - 869. doi:10.1016/S0022-3115(96)00044-X.

[48] M. Reinelt, A. Allouche, M. Oberkofler, C. Linsmeier, Retention mechanisms and binding states of deuterium implanted into beryllium, New Journal of Physics 11 (4) (2009) 043023. doi:10.1088/1367-2630/11/4/043023. 
[49] Y. Fujii, M. Miyamoto, J.-H. Kim, M. Nakamichi, N. Murayoshi, H. Iwakiri, Hydrogen retention behavior of beryllides as advanced neutron multipliers, Nuclear Materials and Energy 9 (2016) 233 - 236. doi:10.1016/j.nme.2016.03.001.

[50] M. Eichler, Investigation of hydrogen isotope retention mechanisms in beryllium: High resolution TPD measurements, Nuclear Materials and Energy 19 (2019) 440 - 444. doi:10.1016/j.nme. 2019.03 .018

[51] A. Kreter, T. Dittmar, D. Nishijima, R. P. Doerner, M. J. Baldwin, K. Schmid, Erosion, formation of deposited layers and fuel retention for beryllium under the influence of plasma impurities, Physica Scripta T159 (2014) 014039. doi:10.1088/0031-8949/2014/t159/014039.

[52] M. Baldwin, T. Schwarz-Selinger, R. Doerner, D retention in Be exposed to fusion relevant mixed species $\mathrm{D}_{2}$-He plasma, Nuclear Materials and Energy 12 (2017) 678 - 682. doi: 10.1016/j.nme.2017.02.006.

[53] A. Založnik, M. J. Baldwin, M. J. Simmonds, R. P. Doerner, Modeling the sharp deuterium release from beryllium co-deposits, Nuclear Fusion 59 (2019) 126027. doi:10.1088/1741-4326/ ab407d.

[54] D. Matveev, M. Zlobinski, G. De Temmerman, B. Unterberg, C. Linsmeier, CRDS modelling of deuterium release from co-deposited beryllium layers in temperature programmed and laser induced desorption experiments, Physica Scripta T171 (2020) 014053. doi:10.1088/ 1402-4896/ab5569 